\title{
Smart city interfaces
}

\author{
Konstantin Semyachkov ${ }^{1,2, *}$ \\ ${ }^{1}$ Institute of economics, the Ural branch of Russian Academy of Sciences, Moskovskaya, 29, \\ Ekaterinburg, Russia \\ ${ }^{2}$ Ural Institute of Management of the Russian Presidential Academy of National Economy and Public \\ Administration, 8 Marta, 66, Ekaterinburg, Russia
}

\begin{abstract}
The work clarifies the concept of a smart city interface as a toolkit for the interaction of digital systems and a wide range of users within the framework of the digitalization of the urban environment. The paper shows that the success of the formation and development of smart cities is associated not only with the introduction of digital technologies in various aspects of the urban environment, but also with the willingness of the population to use these innovations, as well as the toolkit for user interaction with digital systems, i.e. smart city interfaces, their usability and efficiency. The work systematizes the basic principles of the development of interfaces of smart cities, it is shown that the basic principles of creating interfaces are also typical for other digital systems, for example, used in the digitalization of enterprises or individual areas of economic activity. On the other hand, the complexity and multidimensionality of the digital ecosystem of the city requires the development of special principles for the formation of effective tools for interactions within the digital space of the city. The novelty of the research lies in the development of the theoretical foundations of the functioning of modern cities in the context of the formation of a digital society.
\end{abstract}

\section{Introduction}

The concept of a smart city is a systematic innovative view of the functioning of cities in the context of the large-scale use of digital technologies [1]. The idea of a smart city is a vision for urban development that seeks to use multiple digital solutions to address different challenges across multiple aspects of urban development. Despite the fact that digital technologies are a basic component of smart cities, there is an increasing opinion in the scientific community that for the successful development of modern urbanized territories, digital technologies must work in a system with other non-technological elements of cities. In order to be considered smart, a city must go beyond the direction of digitalization of various aspects of the urban environment and strive to synthesize ideas in the direction of sustainable socio-economic development [2]. Moving in this direction will form a city in which digital technologies must merge with traditional infrastructure, which will make the city more functional and competitive. The wider development of modern

\footnotetext{
*Corresponding author: k.semyachkov@mail.ru
} 
cities in the context of digitalization is associated with the expansion of the use of digital technologies in such areas of the urban environment as the management system, public safety, education and health care, transport and utilities [3]. Ultimately, the main goal of implementing the concept of a smart city is to create a single digital eco-environment that would combine all digital subsystems. Such a digital eco-environment is an effective tool for managing the processes taking place in the urban environment. In recent years, cities have significantly revised their development strategies in favor of the large-scale use of digital innovations [4].

The development of digitalization processes of socio-economic systems of different levels, when digital technologies become basic technologies that affect most aspects of modern life, requires the development of new principles of interaction between digital systems of smart cities and users of these systems. In general terms, it can be noted that the toolkit for the interaction of digital systems and users within the framework of the implementation of the concept of a smart city should be convenient and understandable for the majority of the urban population, take into account the social characteristics and interests of the population [5]. Despite a significant amount of research carried out recently and concerning various aspects of the formation of smart cities, mostly related to technological or social aspects, the development of smart city interfaces has not received much attention. Based on this, the goal of this study is to develop the principles of forming effective interfaces of a smart city in the context of digitalization.

Thus, it can be noted that the interfaces of smart cities play a critical role in the overall result of the development of a smart city. The level of general social and technical interaction in the smart city system depends on how effective the tools for user interaction with digital systems of a smart city are. In general, such interaction reflects the success of the development of a smart city, improving the quality of social, economic, environmental and other aspects of the population's life. Introducing innovative solutions to social life can foster citizen participation, develop a shared sense of belonging, aid decision-making, and organize people to achieve collective goals [6].

In general terms, an interface is a collection of tools, methods and rules for interaction between system elements. Within the framework of this study, under the interfaces of a smart city we will understand the toolkit for user interaction with digital systems of the urban environment within the framework of the functioning of the smart city system. Considering the smart city as a socio-technological system, it can be noted that the interfaces of interaction between the digital environment and users play an important socioeconomic role in the development of the urban environment. The development of the urban environment in the context of the formation of a digital society depends on how effectively users can interact with the smart city system. In addition, we note that the importance of considering the problem of developing smart city interfaces is related to the fact that the digitalization processes of modern cities are much more complicated than the processes of traditional objects (enterprises, individual production lines, etc.). Among the distinctive features of the digitalization of modern cities in comparison with simpler objects, it is worth noting that such projects are larger in nature, have greater uncertainty, have greater complexity of organization, since they affect many aspects of the urban environment, have greater involvement of various groups of participants in these processes. Thus, the distinctive features of the processes of digitalization of the urban environment require new principles for the development of interfaces of digital systems in modern cities.

The problems of user interaction with intelligent systems, encompassing engineering solutions, are considered within the framework of the ideas of creating effective humanmachine interfaces (HMIs). The main idea of this concept is the need to create effective jobs within the framework of the functioning of complex technological objects or systems. 
A broader approach to the problems of developing interaction between users and complex digital systems is presented within the framework of the concept of humancomputer interfaces (HCI). This area of research is often viewed as a collection of scientific areas in the field of computer science, behaviorism, design, and other areas of research. Modern research considers the interaction of humans and digital systems as a direction related to the design, evaluation and operation of digital systems for the purpose of their use by humans. In this regard, the problems of studying the processes of user interaction with digital systems are approached from two sides: firstly, this is the study of the human factor, as well as the study of the features of the functioning of digital systems.

The main object for research within the framework of the concept of human-computer interaction in a smart city environment is a number of digital subsystems that have an interface that connects the population and urban components into a single system. Such objects, for example, include the tools of civic participation that allow citizens to participate in the governance of the city. Examples include tools to support democratic processes in municipalities, as well as technologies that collect data within the functioning of urban transport infrastructure and environmental services using mobile sensors. In addition, modern interfaces of urban systems not only provide data of various characteristics to users, but also serve as a data collection tool, using which the population can provide data for their analysis within the framework of smart city systems [7]. Since the use of digital technologies in various fields is mainly aimed at people who do not have special training in the field of digital technologies, in this regard, special attention should be paid to the problems of the development of human-computer interfaces that improve interaction within socio-technological systems [8].

The main objective of research in the field of smart city interfaces is to improve the efficiency of digital systems by achieving more convenient, understandable and responsive to user needs forms of interaction. A long-term task in the interaction of users and digital systems is the development of interfaces that help reduce barriers to building an effective system of interaction within the framework of the smart city model. The creation of effective interfaces for the interaction of users and the digital system of a smart city is the most important task on the way to building an effective management system for modern cities [9]. An important feature of interactions between users and digital systems in a smart city is that, firstly, they are not possible without feedback, and secondly, that digital systems are aimed at solving certain problems and meeting user needs. Based on this, when implementing complex systems as part of the digitalization of certain aspects of modern cities, a user-centered design approach is used, the essence of which is that users should be central to the development of any digital system. As the successful experience of implementing smart city projects shows, an important condition for the digitalization of the urban environment is the joint work of various stakeholders, which makes it possible to clearly express desires, needs and boundaries, and to create a convenient system of interactions that meets these requirements. Since the main stakeholders in the implementation of projects are citizens, who are often not trained users of digital systems, an important factor in the successful implementation of digitalization projects is the creation of user-friendly interfaces of smart cities that allow you to intuitively interact with the digital systems of the urban environment. In this regard, the usability of interfaces is considered as a separate direction in the development of interfaces for complex digital systems, including smart cities.

In general terms, usability is the ability of a system's interface to be understandable to users. The convenience of the system interface in most cases is a factor that allows the user to use the system with the required efficiency, effectiveness and satisfaction. It should be noted that such a characteristic as ease of use is quite subjective and depends on the user's level of preparedness, his personal goals and other features of interaction. In addition, the 
characteristics of the system regarding the convenience of its use often depend on the tasks set, as well as external environmental factors.

One of the known approaches to assessing the usability of certain system interfaces is an approach based on assessing the quality of using digital systems in an urban environment. The concept of quality in use relates to the design and evaluation of interactive digital systems, taking human experience as the central element of the process. In this case, the main standards for assessing the quality of digital systems are ISO 9241, ISO / TR 16982: 2002, ISO / IEC 25010: 2011 standards, which contain requirements, recommendations, models and methodologies for the design and assessment of interactive and human-computer systems. They also demonstrate the centrality of the ease of use of these systems in terms of user focus.

A fairly effective approach to researching smart city interfaces is to study a separate project or initiative that has already been implemented as part of the digitalization of the urban environment. For example, in the study of smart parking interfaces, which were implemented in London, 3 groups of problems were identified related to interfaces and complicating the process of user interaction with the smart parking system [10]. As a result of a study of citizens' opinions regarding interfaces for interacting with digital systems, three areas were identified that led to such a low level of user satisfaction with smart parking lots. The bottlenecks of digital applications include poor usability, persistent technical errors, and functional deficiencies in the application. Another study of the problems of user interaction with smart city applications in the field of tourism made it possible to systematize the factors influencing the effectiveness of user interactions with the application into groups such as active factors, functional factors, basic factors. Among the main directions of the development of interfaces of smart city applications in relation to the tourism sector, the authors highlight areas related to the experience of using such systems, the effective use of the technological component and its interface, as well as the use of tools for sustainable design of digital applications, which is characterized by the adoption of modern rational, economical, technological and friendly solutions that take into account not only existing interests, but also ensure the progressive development of territories for the benefit of future generations, as well as meet the concept of sustainable development $[11,12]$.

Poor app usability is associated with a significant amount of time to understand how an app works, as its user interface design was too complex and confusing, for example, too many steps to register, find a place or make a payment, and other usability issues. Technical errors in the application is the second most common reason for users' refusal to use this application within a smart city. In this regard, an important stage in the development of smart city systems is their testing with the involvement of potential users who will point out the system's flaws, which will reduce unacceptable technical errors. Functional shortcomings include a number of important user requirements that were not satisfied with the current functions of the application.

\section{Research procedure}

As an object of research in this article, we considered the modern concept of digitalization of the urban environment in various manifestations of economic activity. The subject of this study is economic relations that are formed in various areas of the economic application of digital technologies in modern cities. The analyzed data are scientific research reflected in periodicals, as well as the author's results in the framework of the study of digitalization processes in modern cities. The research method is a systematic logical analysis of various stages of digitalization and directions of development of modern cities. 


\section{Results}

In general, the analysis of approaches to the development of interfaces and communication channels of smart cities gives an understanding of the general principles, norms and rules, which can be formulated as follows (Table 1).

Table 1. Principles of development of interfaces of smart cities.

\begin{tabular}{|c|c|}
\hline Principle & Description \\
\hline $\begin{array}{l}\text { The principle of } \\
\text { unambiguity }\end{array}$ & $\begin{array}{l}\text { The clarity and uniqueness of the signals received from various digital } \\
\text { systems when interacting with the components of a smart city is an } \\
\text { important factor in the successful interaction with these components. }\end{array}$ \\
\hline $\begin{array}{l}\text { Top-down } \\
\text { processing } \\
\text { principle }\end{array}$ & $\begin{array}{l}\text { The success of the interaction depends on previous experience with digital } \\
\text { systems. Therefore, if the signal does not agree with previous experience, } \\
\text { then more effort will be required to show that the signal is understood } \\
\text { correctly. }\end{array}$ \\
\hline $\begin{array}{l}\text { Duplication } \\
\text { principle }\end{array}$ & $\begin{array}{l}\text { If a digital system has the ability to represent the same signal in different } \\
\text { formats (text, sound, etc.), the likelihood of successful interaction with } \\
\text { such a system is much higher. }\end{array}$ \\
\hline $\begin{array}{l}\text { The principle of } \\
\text { speculative } \\
\text { realism }\end{array}$ & $\begin{array}{l}\text { The system interface should reflect those real objects that it represents. If } \\
\text { the interface reflects the state of multiple objects, they should appear as if } \\
\text { they were presented in the environment. }\end{array}$ \\
\hline $\begin{array}{l}\text { The principle of } \\
\text { minimizing the } \\
\text { time of access } \\
\text { to information }\end{array}$ & $\begin{array}{c}\text { The interface of smart city systems should provide access to information in } \\
\text { the fastest and most convenient way. }\end{array}$ \\
\hline $\begin{array}{l}\text { Compatibility } \\
\text { principle }\end{array}$ & $\begin{array}{l}\text { Within the framework of performing one task, it is possible to divide } \\
\text { attention into several interface elements, which should not affect the } \\
\text { temporal characteristics, the level of convenience of interactions with the } \\
\text { system and other indicators. }\end{array}$ \\
\hline $\begin{array}{l}\text { The principle of } \\
\text { visibility }\end{array}$ & $\begin{array}{l}\text { The interface of the smart city system should be clear and understandable } \\
\text { for various categories of citizens, including unprepared users. }\end{array}$ \\
\hline $\begin{array}{l}\text { The principle of } \\
\text { proactivity }\end{array}$ & $\begin{array}{l}\text { The system interface should be configured for proactive actions, consisting } \\
\text { in helping and solving problems even before the moment when the user } \\
\text { encountered them. }\end{array}$ \\
\hline $\begin{array}{l}\text { The principle of } \\
\text { engagement }\end{array}$ & $\begin{array}{c}\text { In the development of smart city interfaces, various groups of participants } \\
\text { and stakeholders should be involved in order to take into account the views } \\
\text { of various user groups when building effective tools for interaction } \\
\text { between digital systems and users. }\end{array}$ \\
\hline $\begin{array}{l}\text { The principle of } \\
\text { uniformity }\end{array}$ & $\begin{array}{l}\text { An effective approach to the creation of interfaces for various smart city } \\
\text { systems is the development of uniform standards that determine the main } \\
\text { characteristics of the interfaces of urban systems. In addition, common } \\
\text { approaches to the interfaces of various systems are most often combined } \\
\text { within a digital platform that combines different interfaces of digital } \\
\text { systems into a single smart city platform. }\end{array}$ \\
\hline $\begin{array}{l}\text { Accessibility } \\
\text { principle }\end{array}$ & $\begin{array}{l}\text { Smart city services should also be made available through more traditional } \\
\text { means of interaction (for example, through specialized assistants, } \\
\text { specialists and consultants who can help provide the service to an } \\
\text { unqualified user). }\end{array}$ \\
\hline
\end{tabular}

Analysis of the conditions for the success of the implementation of projects for the digitalization of the urban environment shows the importance of developing tools for user interaction with the digital components of smart cities. In this regard, smart city interfaces, 
as well as communication channels of users and digital systems, are a critical factor in the formation and development of smart city systems. In this regard, special attention should be paid to the development of smart city interfaces on the part of all stakeholders; in the implementation of projects to digitize various aspects of the urban environment, specialists in the field of research of interfaces of digital systems should be involved. In addition, a reasonable solution would be to form a general plan for the development of tools for interaction of digital systems with the user community within a specific territory, as well as the creation of regulations and standards in this area based on the experience of cooperation and partnerships with stakeholders.

\section{Discussion}

The concept of urban development based on the introduction of digital technologies into various aspects of the urban environment is gaining more and more supporters in the modern world. It is digital technologies, big data, artificial intelligence and other innovations in this area that are considered as the main driver of the development of modern cities. At the same time, it should be noted that the city will develop only if the changes taking place in the urban environment, digital technologies that will be introduced into the urban environment to solve certain problems, will in fact be useful for users, convenient to use, accessible and understandable to most citizens. From our point of view, if this condition is not met, digitalization runs the risk of happening only for the sake of digitalization, acting as a PR tool for local authorities or a means for making money for private companies, and not as a tool to improve the quality of life of citizens. Based on this, the most important factor in the implementation of the concept of a smart city is the creation of an effective toolkit for user interaction with digital systems of the city, that is, smart city interfaces.

In the present study, which was carried out with the aim of developing the principles of effective construction of smart city interfaces, the following results were obtained.

First, it is shown that the toolkit for the interaction of users and digital systems of a smart city play a crucial role in the digitalization of the urban environment. In this regard, the concept of a smart city interface has been introduced, its meaning has been determined.

Secondly, the aspects of the analysis of the functioning of smart cities in the context of the study of interfaces of a smart city are revealed.

Third, the main principles of the development of smart city interfaces are summarized.

The theoretical significance of this study lies in the analysis of the principles of the development of interfaces of smart cities. The practical significance of the study lies in shaping possible future studies of smart management in a digital society.

\section{Acknowledgements}

This work was supported by the Grants Council of the President of the Russian Federation, project MK-526.2020.6.

\section{References}

1. E. V. Pakhomov, Engineering Bulletin of the Don, 3 (46), 72-82 (2017)

2. V. Angelakis et al. (eds.), Designing, Developing, and Facilitating Smart Cities (Springer, Cham, 2017) 
3. A. I. Artemova, R. K. Nurmukhametov, Bulletin of the Tula branch of the Financial University, 1-1, 53-61 (2019)

4. D. G. Vladimirov, A. M. Vorotnikov, Bulletin of the Russian University of Cooperation, 3 (33), 17-21 (2018)

5. T. S. Sergeeva, City management: theory and practice, 1 (4), 46-51 (2012)

6. O. E. Medvedeva, Modern Economy Success, 2, 5-11 (2019)

7. E. Christopoulou, D. Ringas \& J. Garofalakis, LNCS, 8530, 545-554 (2014)

8. D. McMillan, LNCS, 10673, 119-131 (2017)

9. Y. Liu, LNCS, 10918, 101-111 (2018)

10. P. V. Stroyev, S.B. Reshetnikov, Economy in industry, 10 (3), 207-214 (2017)

11. G. C. A. Peng, M. B. Nunes, L. Zheng, Information Systems and e-Business Management, 15 (4), 845-876 (2016)

12. P. Liu, \& Y. H. Pan, LNCS 8528, 668-675 (2014). Access mode: doi:10.1007/978-3319-07308-8_64 